\title{
Photocatalytic degradation of orange II by titania addition to sol-gel glasses
}

Inorganic Chemistry Area, Inorganic and Organic Department. Jaume I University, 12071 Castellón, Spain.

*Corresponding author: e-mail address: jbadenes@qio.uji.es telephone: 964728231. Fax: +34964728214

\begin{abstract}
Glasses with $\mathrm{SiO}_{2}-\mathrm{CaO}-\mathrm{ZnO}-\mathrm{B}_{2} \mathrm{O}_{3}-\mathrm{K}_{2} \mathrm{O}-\mathrm{Al}_{2} \mathrm{O}_{3}$ composition modified by addition of titania $(3,5,12$ and $20 \% \mathrm{w})$ have been prepared by sol-gel method. The obtained gels were aged, dried and fired at $600^{\circ} \mathrm{C} / 1 \mathrm{~h}$ in order to stabilise the glass. The resulting fired powders were characterised by UV-Vis-NIR spectroscopy, scanning electron microscopy (SEM), transmission electron microscopy (TEM) and X-ray diffraction (XRD). Their photocatalytic capacity on the degradation of orange II dye has been studied. The XRD and TEM results indicate that system is amorphous with a nanostructured microstructure. From UV-Vis-NIR results the band gap calculated is around $3.5 \mathrm{eV}$ for all samples. Photoactivity of powders depends on amount of titania in glass composition and the surface area of prepared samples. The sample with highest surface area and lowest addition of titania (3\% w. sample) shows similar activity than commercial anatase used as reference.
\end{abstract}

Keywords sol-gel, photocatalysis, ceramic glass, orange II, titania

\section{Introduction}

Decolourization of dye effluents has received increasing attention and the advanced oxidation processes have been growing during the last decade since they are able to deal with the problem of dye destruction in air and aqueous systems. Heterogeneous photo catalysis can be considered as a one of this new oxidation processes [1]. In this kind of catalysis the photonic activation is the mode to active the catalyst and the photon energy is adapted to absorption of the catalyst, not to that of the reactants. When semiconductor catalyst is illuminated with adequate photons (energy equal or greater than band-gap energy of catalyst $h v \geq E g$ ) they are absorbed and electron-hole pairs are created within the bulk as previous step to electron or hole transfer towards reactants. The photoinduced transfer of electrons depends on the band-edge position of the semiconductor and the redox potentials of the adsorbates [2]. The photoefficiency can be reduced by the electron-hole recombination which corresponds to the degradation of the photoelectric energy into heat. Furthermore, heterogeneous photocatalysis is influenced by catalyst loading, initial pollutant concentration, $\mathrm{pH}$, radiant flux, aeration, 
presence of other substances or impurities, photoreactor geometry and particle properties of catalyst (particle size, crystal structure, crystallinity, defects and preparation method $[3,4]$.

An ideal photocatalyst is characterised by the following attributes [5]: Photostability, chemically and biologically inert nature, availability and low cost and capability to adsorb reactant under efficient photonic activation. In the other hand, an easy removal of the catalyst after the irradiation treatment is needed in order to recycling of catalyst, e.g. easy sedimentation of suspended catalyst particles. Many semiconductors such us $\mathrm{TiO}_{2}, \mathrm{ZnO}, \mathrm{ZrO}_{2}, \mathrm{CdS}, \mathrm{MoS}_{2}$ have been examined for the degradation of organic contaminants [6] but the anatase polymorph of titania is reported as the best combination of photoactivity and photostability $[7,8]$. Titania has been used either as free fine or larger particles or as coating on a substrate. In the last case, many kinds of supports have been studied which include soda lime glass, aluminium, ceramic tiles and coated glass [9]. However, few papers have studied the photocatalytic activity of amorphous or less crystallized $\mathrm{TiO}_{2}$ [10,11]. The results reported the negligible activity of amorphous $\mathrm{TiO}_{2}$ by comparison with commercial crystalline titania catalyst. Ohtani et al [11] attributed this low activity to electron-hole recombination at defects located on the surface and in the bulk of particles. It is commonly accepted that amorphous metal oxides contain high concentrations of defects that will decrease the photo-efficiency. In spite of these considerations, several recent studies show that amorphous forms of $\mathrm{ZrO}_{2}$ [12] and $\mathrm{Nb}_{2} \mathrm{O}_{5}$ [13] exhibit higher photoactivity than their crystalline forms. In addition, Zhang and Maggard [14] reported the preparation by coprecipitation method of hydrated forms of amorphous titania with significant photocatalytic activity which is associated with an increase of active sites from synthesis method and reduced electron-hole recombination.

The azo compounds are one of the most important groups of dyes used in photocatalytic processes. Among the azo dyes the orange II can be considered as a model compound for oxidative degradation studies and it has been investigated extensively on different catalysts [4,15-17].

Recently, the capacity on the degradation of orange II of some ceramic glasses after the corresponding devitrification processes has been investigated. The results indicate that an acceptable photocatalytic activity was reached [18] which have increased the motivation to this work.

The aim of this paper is the synthesis by sol-gel method of a conventional glass used in ceramic industry alloyed with increasing amounts of $\mathrm{TiO}_{2}$ in order to study its photocatalytic activity on the degradation of orange II monoazo dye. Several gains of using glass agglomerates instead fine $\mathrm{TiO}_{2}$ particles can be drawn: a) the easy sedimentationn of the catalyst after the irradiation treatment and consequently their easy reciclying. b) the homogeneity achieved using sol-gel procedure allows to attain a material with low concentration of defects increasing active sites and reducing electronhole recombination. c) the preparation of sol-gel glass is not more expensive than the complex synthesis of fine $\mathrm{TiO}_{2}$ particles used on photo-catalysis such as the Panreac Anatase used as reference in this work, the patented $\mathrm{TiO}_{2}$ photocatalyst Degussa P25 standard material, a three-phase mixture of the amorphous, anatase and rutile forms of $\mathrm{TiO}_{2}$ arranged in a complex microstructure [19] or the best efficient titania photocatalyst reported by Basca and Kiwi [20] obtained by hydrolysis of tetraisopropyl-orthotitanate followed by densification under hydrothermal conditions $(1500-4000 \mathrm{kPa})$.

\section{Experimental procedure}


The oxide composition of selected ceramic glass and the chemical precursors, and their suppliers, used in the synthesis are shown in Table 1. To this composition increasing amounts of $\mathrm{TiO}_{2}$ were added (T1, T5, T12 and T20 labelled samples for 3, 5, 12 and $20 \% \mathrm{TiO}_{2}$ weight respectively). Titanium isopropoxide $\mathrm{Ti}\left(\mathrm{OCH}\left(\mathrm{CH}_{3}\right)_{2}\right)_{4}$ supplied by Aldrich was used as precursor of $\mathrm{TiO}_{2}$ oxide.

Table 1 Oxide composition of selected glass.

\begin{tabular}{|c|c|l|}
\hline oxide & weight (\%) & \multicolumn{1}{|c|}{ Precursor(supplier) } \\
\hline $\mathrm{SiO}_{2}$ & 50 & $\mathrm{TEOS}($ Alfa Aesar) \\
\hline $\mathrm{CaO}$ & 18 & $\mathrm{Ca}\left(\mathrm{NO}_{3}\right)_{2} \cdot 4 \mathrm{H}_{2} \mathrm{O}($ Panreac $)$ \\
\hline $\mathrm{K}_{2} \mathrm{O}$ & 4 & $\mathrm{KNO}_{3}($ Panreac $)$ \\
\hline $\mathrm{Al}_{2} \mathrm{O}_{3}$ & 8 & $\mathrm{Al}\left(\mathrm{NO}_{3}\right)_{3} \cdot 4 \mathrm{H}_{2} \mathrm{O}($ Panreac $)$ \\
\hline $\mathrm{ZnO}$ & 12 & $\mathrm{Zn}\left(\mathrm{NO}_{3}\right)_{2} \cdot 4 \mathrm{H}_{2} \mathrm{O}($ Panreac $)$ \\
\hline $\mathrm{B}_{2} \mathrm{O}_{3}$ & 8 & $\mathrm{~B}(\mathrm{OH})_{3}($ Panreac $)$ \\
\hline
\end{tabular}

The samples were prepared by sol-gel method following the next steps. Firstly, stoichiometric amount of boric acid to prepare $20 \mathrm{~g}$ of the glass was solved with continuous stirring to $150 \mathrm{ml}$ of water previously heated at $70^{\circ} \mathrm{C}$. Then nitrates precursors of zinc, aluminium, potassium and calcium were added successively maintaining continuously stirring and $70{ }^{\circ} \mathrm{C}$. Then tetraethylorthosilicate (TEOS) was dropped, and finally titanium isopropoxide was dropped into the media obtaining a suspension $(\mathrm{pH}=2.5)$. Finally, ammonia water solution $(15 \%)$ was dropped until gelation occurred at $\mathrm{pH}=8$. This gel was aged at room temperature during 24 hours in the open air and dried at $110^{\circ} \mathrm{C}$ during 12 hours. Then it was manually milled in acetone media in an agate mortar during 20 minutes and fired at $600^{\circ} \mathrm{C} / 1$ hour in order to stabilise the glass and avoid the devitrification process as in previous work [18].

Resulting powders were characterised by BET (Brunnauer, Emmett and Teller) analysis, UV-vis-NIR spectroscopy, scanning electron microscopy (SEM), transmission electron microscopy (TEM) and X-ray diffraction (XRD).

The surface area of the fired samples was determined by BET analyses using $\mathrm{N}_{2}$ in an ASP 2010 (Micrometrics Co.) analyzer.

UV-Vis-NIR spectroscopy using the diffuse reflectance technique was carried out with a Perkin-Elmer (lambda 2000) spectrophotometer in the range 200-800 $\mathrm{nm}$ in order to obtain the band-gap of catalyst from the absorption threshold wavelength.

The microstructure of representative fired samples was studied by Scanning Electron Microscopy, using a Leo-440 Leyca electron microscope equipped with an Energy Dispersion X-ray (EDX) attachment by Oxford University (work conditions 10$20 \mathrm{kV}$ acceleration voltage and a probe intensity of 150-500 pA). The EDX analysis was obtained at relatively low magnification as an average of the area of the image on the scanning electron microscope screen. Samples were graphite coated by a sputtering procedure before SEM-EDX studies.

The morphology of fired powders were also examined using transmission electron microscopy (model H-800, Hitachi Ltd, Tokyo, Japan) at an accelerating voltage of $150 \mathrm{kV}$. Electron-diffraction patterns (SAED: selected area electron diffraction) were also obtained on the same transmission electron microscope equipped with a rotating and tilting goniometric stage.

XRD patterns were obtained in a Siemens D-500 diffractometer with Ni filtered $\mathrm{Cu} \mathrm{K} \alpha$ radiation between 10 and $70^{\circ} 2 \theta$.

The photocatalytic tests were carried out using a suspension of $500 \mathrm{mg} / \mathrm{l}$ of powder added to a solution $0.6 \cdot 10^{-5} \mathrm{M}$ of orange II in a $\mathrm{pH} 7.42$ phosphate buffer media 
$\left(\mathrm{NaH}_{2} \mathrm{PO}_{4} \cdot \mathrm{H}_{2} \mathrm{O} 3.31 \mathrm{~g}\right.$ and $\mathrm{Na}_{2} \mathrm{HPO}_{4} \cdot 7 \mathrm{H}_{2} \mathrm{O} 33.77 \mathrm{~g}$ solved in $1.000 \mathrm{ml}$ of water). The solution $0.6 \cdot 10^{-5}$ of monoazo dye in buffer media was analyzed by UV-vis-NIR to determinate the adequate wavelength to measure the aliquot illuminated. The results indicate that $\lambda=485 \mathrm{~nm}$ was the maximum of absorbance. The UV irradiation source was a mercury lamp of $125 \mathrm{~W}$ emitting in the range $254-365 \mathrm{~nm}$. The suspension was first stirred in the dark for $15 \mathrm{~min}$ to reach equilibrium sorption of the dye. Aliquot samples were taken every 15 min to measure the change in the dye concentration by spectroscopy at the maximum of absorbance. Photo-stability and easy removal by sedimentation of the catalyst were checked repeating thrice the above-mentioned photocatalityc test using the recycled powders.

Blank experiments with orange II solution and without catalyst, were conducted before the photocatalytic experiments. Likewise commercial anatase supplied by Panreac S.A. was used as reference to compare its photo-catalytic activity with the prepared samples.

\section{Results and discussion}

\subsection{Characterisation of fired powders}

The XRD patterns of prepared samples and $\mathrm{TiO}_{2}$ powders used as reference are shown in Fig. 1.: anatase is the only crystalline phase detected in titania powders and all prepared glasses become amorphous at XRD.

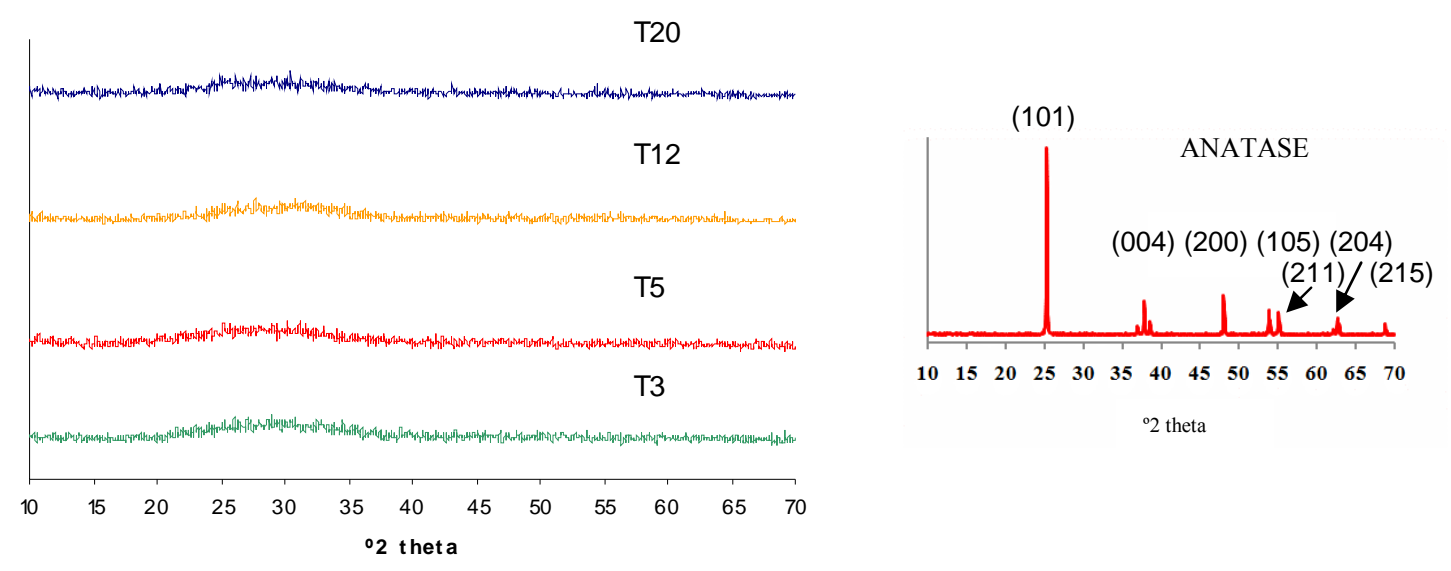

Fig 1 XRD patterns of fired powders at $600^{\circ} \mathrm{C} / 1 \mathrm{~h}$ and PANREAC anatase used as reference

There are not different results among samples from the UV-Vis-NIR spectra as can be observed in Fig. 2. The spectra are dominated by a broad band in ultraviolet region centred at $260 \mathrm{~nm}$ associated to metal-ligand charge transfer $\left(\mathrm{Ti}^{4+} \leftrightarrow \mathrm{O}^{2-}\right)$ in titania. From the threshold value of absorbance the band gap calculated for all compositions is $3.80 \mathrm{eV}$. The same value calculated for anatase is $3.23 \mathrm{eV}$ in agreement with the literature [9]. 


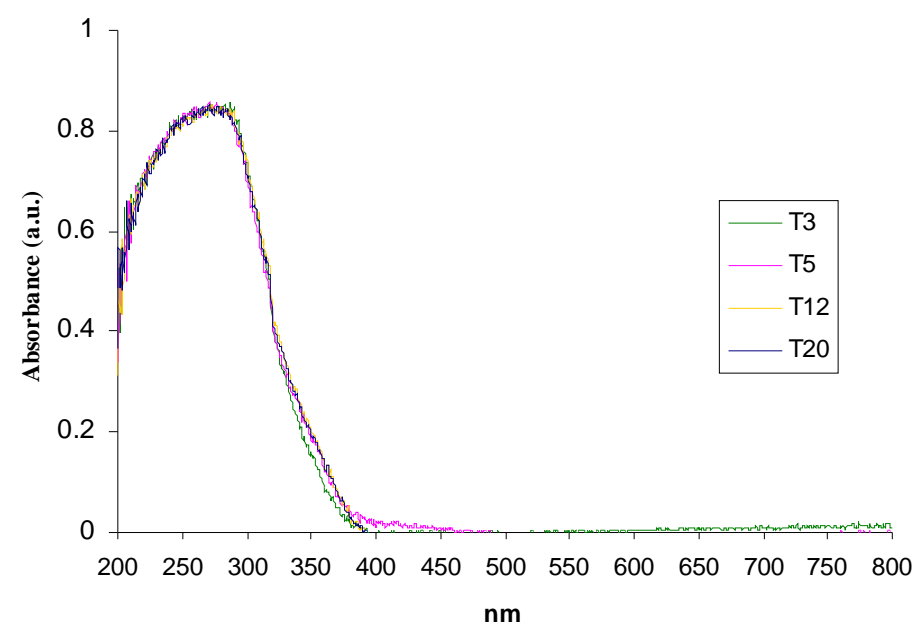

Fig. $2 \mathrm{UV}-\mathrm{Vis}$ spectra of fired powders at $600^{\circ} \mathrm{C} / 1 \mathrm{~h}$

The microstructure of representative $\mathrm{T} 3$ sample fired at $600^{\circ} \mathrm{C} / 1 \mathrm{~h}$ and its chemical analysis EDX is shown in Fig. 3.a. Heterogeneous distribution of glass aggregates in the range 10-1 $\mu \mathrm{m}$ can be observed in Fig.3.a. But particles lower than 1 $\mu \mathrm{m}$ of size can be observed forming agglomerates at higher magnification (Fig. 3.b). The chemical composition by EDX analysis (Fig. 3.c) reveals the results are according to the composition formulated (the greatest peak observed on Fig. 3.c closest to y axis is due to sputtered graphite coating). Homogenous distribution of chemical elements may be appreciated in representative sample from EDX mapping showed in Fig. 4.

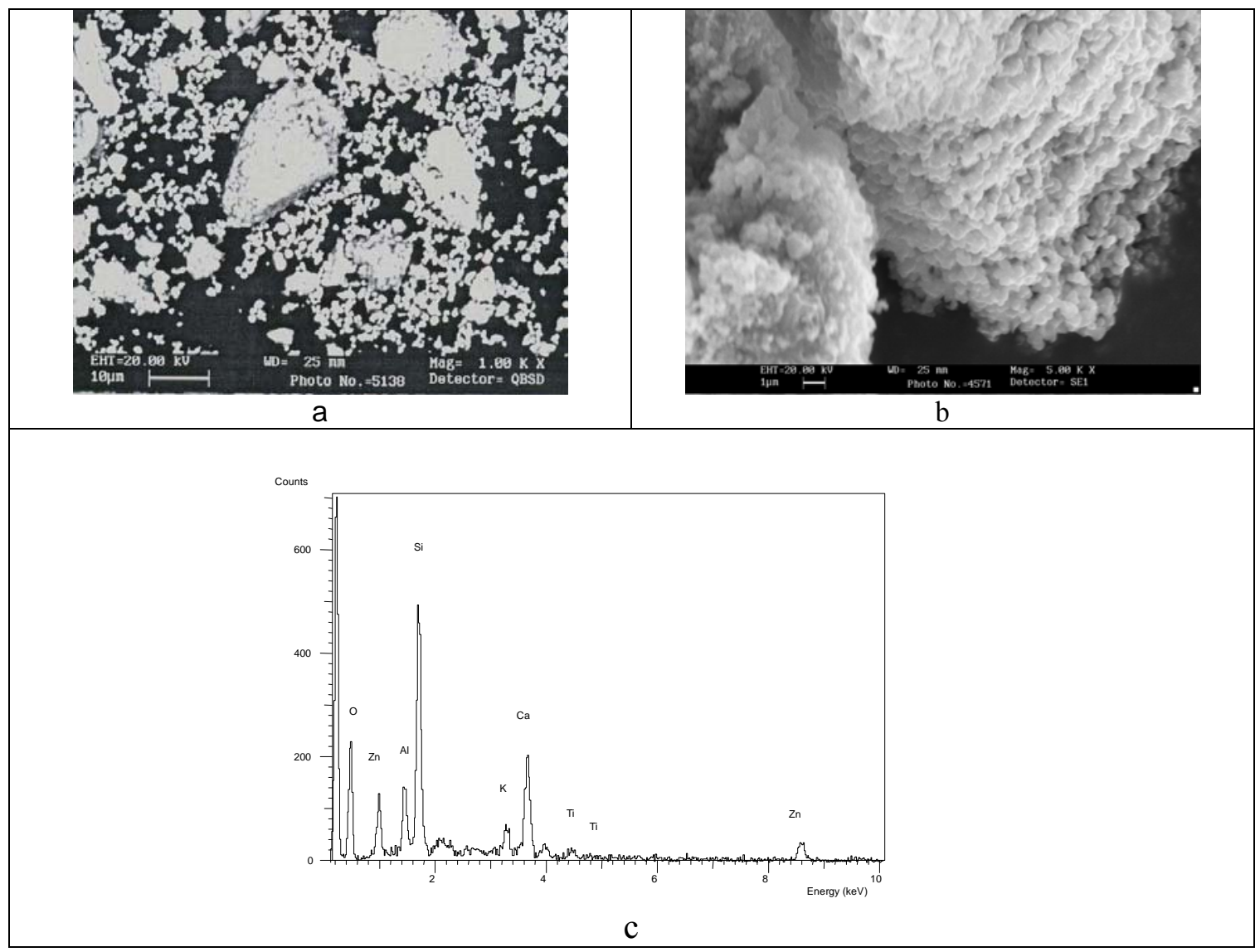


Fig. 3 The microstructure of representative sample (T3) fired at $600^{\circ} \mathrm{C} / 1 \mathrm{~h}$ and its chemical analysis EDX

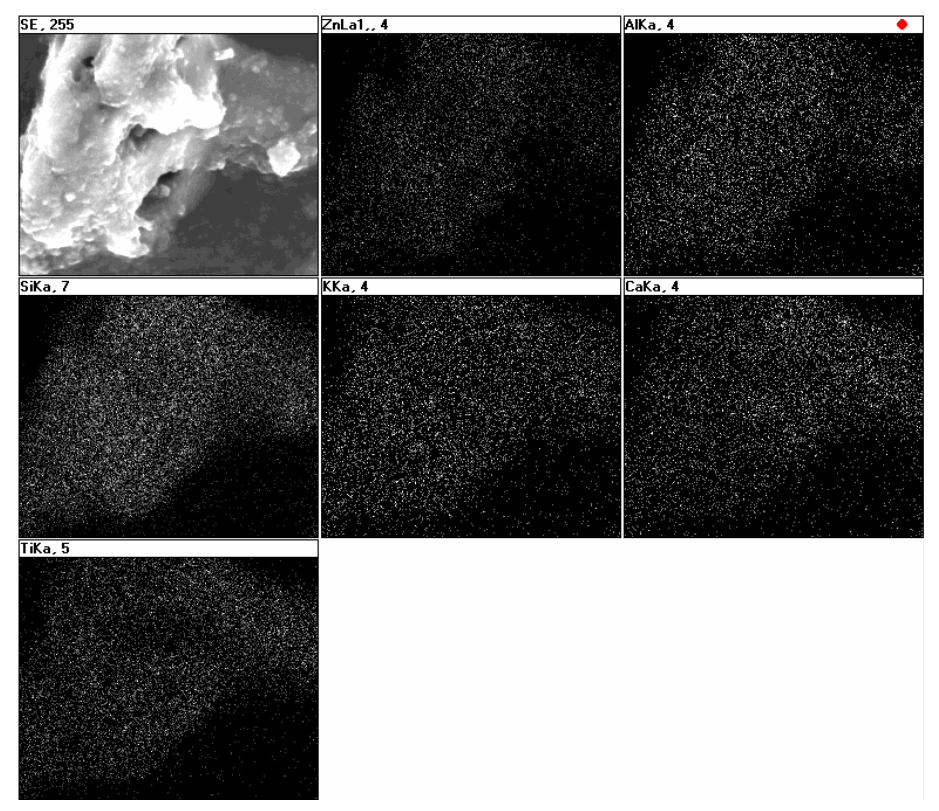

Fig 4 EDX mappings of $\mathrm{T} 3$ sample fired at $600^{\circ} \mathrm{C} / 1 \mathrm{~h}$

Further microstructure details of representative fired T3 sample obtained by TEM and SAED patterns are shown in Fig. 5. TEM observations show nanoparticles around 40-70 nm of size in agreement with SEM above mentioned and confirming the nanostructured nature of powders. The electron diffraction pattern indicates the sample remains amorphous in agreement with XRD results above discussed. EDX and TEMSAED analysis of other glasses are similar to the observed for the T3 representative sample.

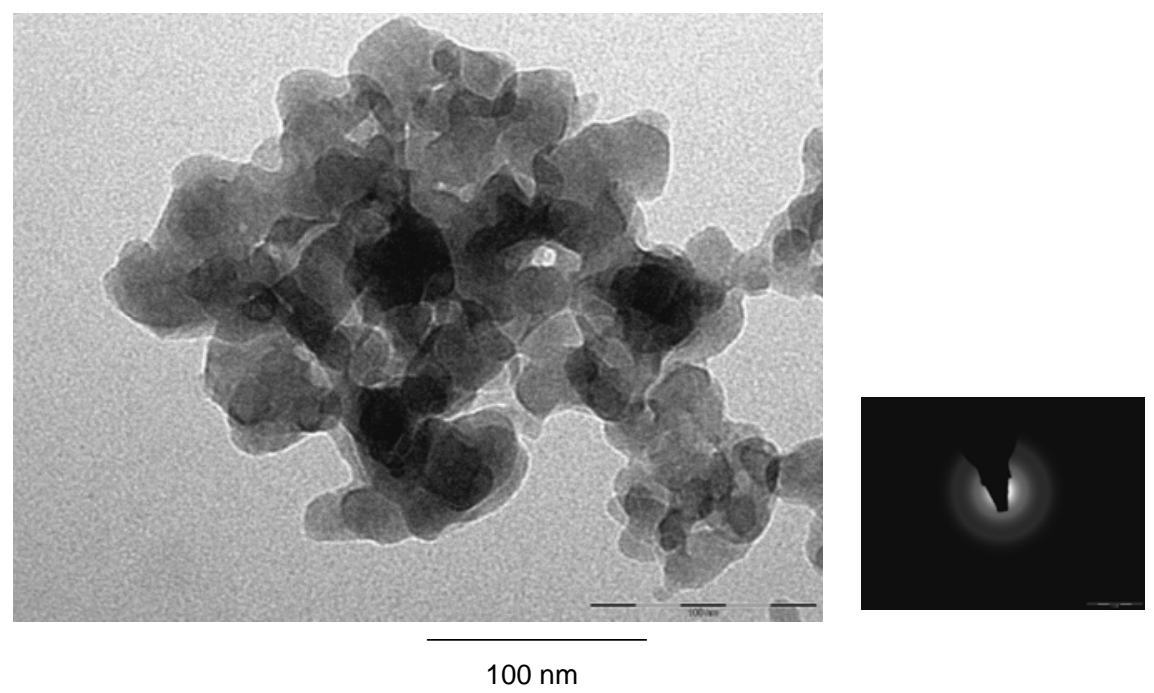

Fig. 5 TEM micrograph of T3 fired sample and SAED pattern of the same sample 
The specific surface area values of samples obtained by nitrogen absorption using BET method are given in Table 2. Sample T3 has the highest specific surface area value that decrease regularly from T5 to T20 compositions. Although from XRD, SEM and TEM analysis no significant differences are observed among prepared samples, the titania has been able to carry out a nucleation effect as occur in devitrification processes of ceramic glasses whose result leads to a diminution of surface area of samples. On the other hand, anatase presents lower surface area than the richest titania sample. This fact can be explained from the high crystallinity of commercial anatase detected by XRD in Fig 1.

Table 2. BET specific surface area of powders fired at $600^{\circ} \mathrm{C} / 1 \mathrm{~h}$ (standard deviations in parenthesis)

\begin{tabular}{|c|c|}
\hline Samples & $\mathbf{~}^{2} / \mathbf{g}$ \\
\hline T3 & $76.5(5)$ \\
\hline T5 & $67.0(4)$ \\
\hline T12 & $31.9(2)$ \\
\hline T20 & $18.5(1)$ \\
\hline anatase (reference) & $9.17(3)$ \\
\hline
\end{tabular}

\subsection{Photocatalytic test}

The photocatalytic activity test of samples was carried out as above mentioned experimental procedure. The change in the dye concentration from initial concentration $\left(\mathrm{C}_{0}\right)$ is given in Fig.6. The results indicate a linear degradation curve of orange II solution in the "blank" test carried out without catalyst. This linear behaviour is in agreement with the photolyisis effect of UV irradiation in absence of catalyst. The presence of catalyst produces an exponential decay of the dye concentration due to their photocatalytic capacity. The best photocatalytic yield, similar to anatase used as reference, was reached in $\mathrm{T} 3$ sample.

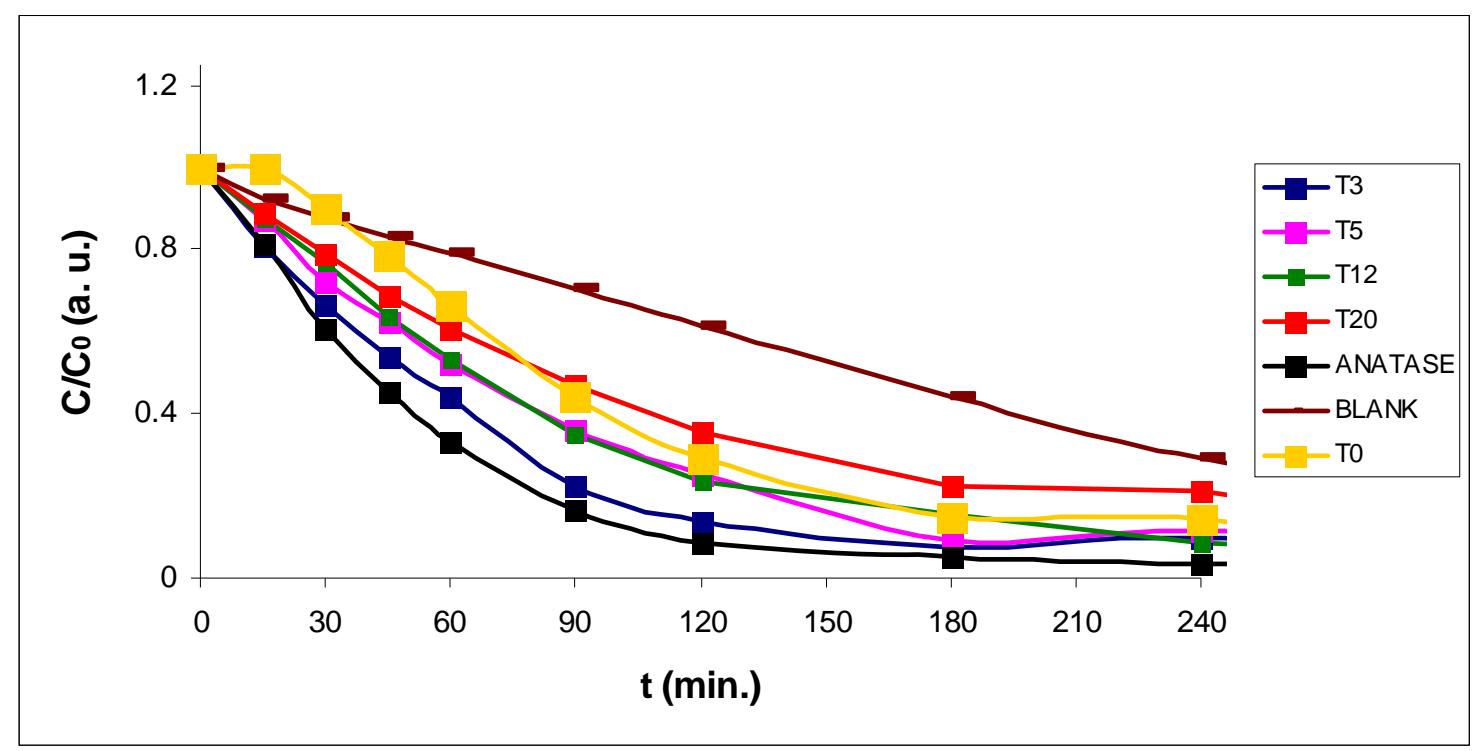

Fig 6 Photocatalytic degradation curves of orange II under UV light using blank, anatase and prepared samples 
Exponential decay of the dye concentration of photocatalytic oxidation of different dyes fitted the Langmuir-Hinshelwood (L-H) kinetics model [19,20,21]. When the initial concentration $(\mathrm{Co})$ and the adsorption are low the kinetic model follow the equation:

$$
\ln \frac{C}{c_{0}}=k K t=K_{a p p} t
$$

Where $\mathrm{t}=$ illumination time, $\mathrm{C}=$ actual dye concentration

A plot of $\operatorname{lnC}_{\mathrm{o}} / \mathrm{C}$ versus time becomes a straight line and the slope of the linear regression equals the apparent first-order rate constant $\mathrm{K}_{\mathrm{app}}$. From $\mathrm{K}_{\mathrm{app}}$ constant the half life time $\left(\mathrm{t}_{1 / 2}\right)$ can be calculated following the next expressions:

$$
\ln \frac{c_{0} / 2}{c_{0}}=K_{a p p} t_{1 / 2} \quad t_{1 / 2}=-\frac{\ln 2}{K_{a p p}}
$$

The plots of $\ln (\mathrm{C} / \mathrm{Co})$ versus time from kinetic degratadation data on Fig. 6 are shown in Fig. 7. Experimental data are in agreement with the L-H model because the lineal behaviour of each curve indicates that a first order reaction is taking place during orange II degradation. The kinetics parameters of the photocatalytic reaction $t_{1 / 2}$ and the square of the correlation coefficient $\mathrm{R}^{2}$ calculated from above equations are given in Table 3 indicates a goodness-of-fit measure.

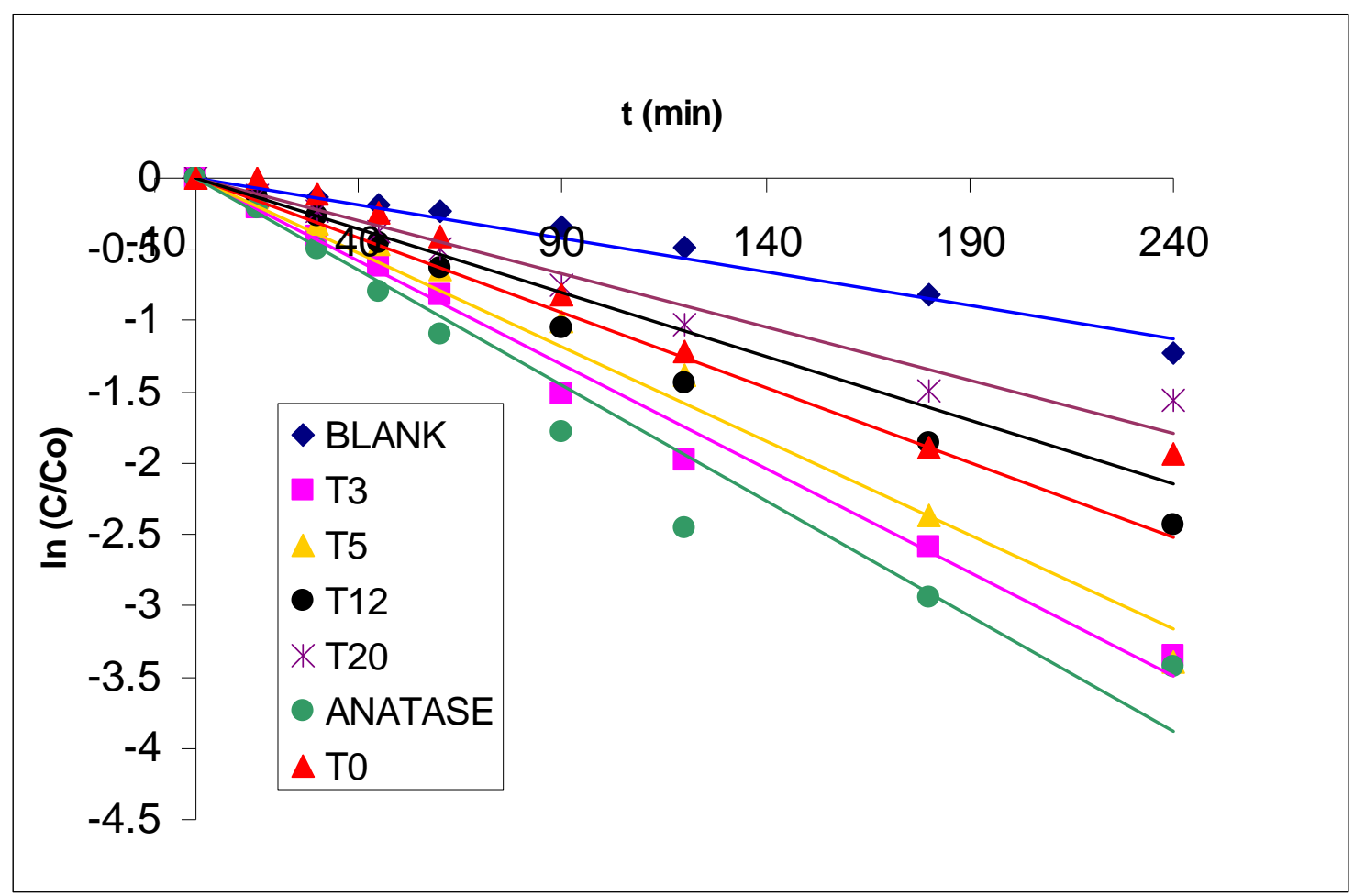

Fig. 7 .L-H kinetic model for the reaction degradation of orange II. 
Table 3 Kinetic parameters of the degradation reaction of orange II

\begin{tabular}{|c|c|c|}
\hline Sample & $\mathbf{t}_{\mathbf{1 / 2}} \mathbf{( m i n )}$ & $\mathbf{R}^{\mathbf{2}}$ \\
\hline $\mathrm{T} 0$ & 78 & 0.9528 \\
\hline $\mathrm{T} 3$ & 47 & 0.9891 \\
\hline $\mathrm{T} 5$ & 58 & 0.9833 \\
\hline $\mathrm{T} 12$ & 66 & 0.9903 \\
\hline T20 & 87 & 0.9614 \\
\hline Blank & 180 & 0.9813 \\
\hline anatase (reference) & 42 & 0.9517 \\
\hline
\end{tabular}

The high half time life of blank sample related to prepared samples indicates that the direct photolysis of the dye is negligible as above mentioned. The results indicate that photoactivity decreases when the titanium amount increases in glass composition and the $\mathrm{t}_{1 / 2}$ is higher and higher from $47 \mathrm{~min}$ in T3 sample to $87 \mathrm{~min}$. in T20 sample. In addition, the photoefficiency of $\mathrm{T} 3$ sample is similar to anatase.

To obtain highly active catalyst it necessary to give simultaneously two properties, generally of contradiction, to the powders: large surface area to adsorb substrates and high crystallinity (or lesser surface and bulk defects) to diminish the electron-hole combination. From the amorphous nature of ours samples, the surface area is the most important property that explains the results obtained. Actually, the samples with larger surface, especially T3 sample, with wider band energy gap than anatase (3.8 $\mathrm{eV}$ front $3.2 \mathrm{eV}$ ) has significant photocatalytic activity. The lower and lower measured surface area and the higher and higher concentrations defects, that could be associated to amorphous metal oxides due to increasing of titanium doping, lead to decrease the catalytic activity from T3 to T20. On the other hand, the low surface are of anatase is compensated by the high crystallinity of this $\mathrm{TiO}_{2}$ phase.

According to the kinetics parameters, the best photocatalytic activity was observed for T3 sample which presented a half time life of $47 \mathrm{~min}$. similar to crystalline anatase used as reference. The photoactivity of glasses depends on amount of titanium dispersed in glass and the surface area of samples.

\section{Conclusions}

The resulting powders in the system $\mathrm{SiO}_{2}-\mathrm{CaO}-\mathrm{ZnO}-\mathrm{B}_{2} \mathrm{O}_{3}-\mathrm{K}_{2} \mathrm{O}-\mathrm{Al}_{2} \mathrm{O}_{3}$ with increasing amount of titanium obtained by sol-gel method from alcoxides and nitrates are amorphous from XRD and TEM analysis with a nanostructured microstructure. The study of catalytic activity of the samples determined by degradation of Orange II dye shows that a first order reaction according with Langmuir-Hinshelwood model is followed. The photoactivity of powders depends on amount of titanium in glass composition and the surface area of prepared samples. The T3 compositions presents similar activity than referenced anatase with the kinetic parameters $\mathrm{K}_{\mathrm{app}}=0.0147$ and $\mathrm{t}_{1 / 2}=47 \mathrm{~min}$.

\section{Ackonowledgements}


We gratefully acknowledge tha financial support given by MCYT, MAT 2005-0057 project and by FUNDACION CAJA CASTELLÓN, P1-1B2005-06 project.

\section{References}

[1] Herrmann JM (1999) Catal Today 53:115

[2] Fujishima A, Rao TN, Tryk DA (2000) J Photochem Photobiol C 1:1

[3] Jang HD, Kim S-K, Kim S-J (2001) J Nanoparticle Res 3:141

[4] Konstantinou IK, Albanis TA (2004) Appl Cata B: Environ 49:1

[5] Carp O, Huisman CL, Reller A (2004) Prog Solid State Chem 32:33

[6] Konstantinou IK, Sakkas VA, Albanis TA (2002) Water Res 36:2733

[7] Bojinova A et al (2007) Mat Chem Phys 106:187

[8] Jensen $\mathrm{H}$ et al (2004) J Nanoparticle Res 6:519

[9] Gaya UI, Abdullah AH (2008) J Photochem Photobiol C 9:1

[10] Tanaka K, Capule MFV, Hisanaga T (1991) Chem Phys Lett 187:73

[11] Othani B, Ogawa Y, Nishimoto SI (1997) J Phys Chem B 101:3746

[12] Wu CY et al (2005) J Mol Cata A: Chem 229:233

[13] Kominami H et al (2001) J Mater Chem 11:604

[14] Zhang Z, Maggard PA (2007) J Photochem Photobiol A 186:8

[15] Betianu C et al (2008) J Chem Technol Biotechnol 268

[16] Daneshvar N et al (2007) J Hazard Mater 143:95

[17] Villanueva SF, Martinez SS (2007) Sol energy Mater Sol Cells 9:492.

[18] Ruiz O. Sanmiguel F, Garcori C et al (2008) QUALICER2008 15

[19] Hotsenpiller P.A.M., Bolt J.D., Farneth W.E., Lowekamp J.B., Rohrer G.S. (1998), J. Phys. Chem. B 102:3216.

[20] Bacsa R.R., Kiwi J. (1998), Appl. Catal. B Environ. 16 :19.

[19] Langmuir (2000) Environ Photochem 16:1102

[20] Haouas A et al (2001) Apll Catl B: Environ 31:145

[21] Torres-Martinez L et al (2008) JSol-Gel Sci Technol 47:158 
C.S. Choi, T Yun, US Patent 6447686 - Rapid coagulation-flocculation and sedimentation type waste water treatment method. 
T20

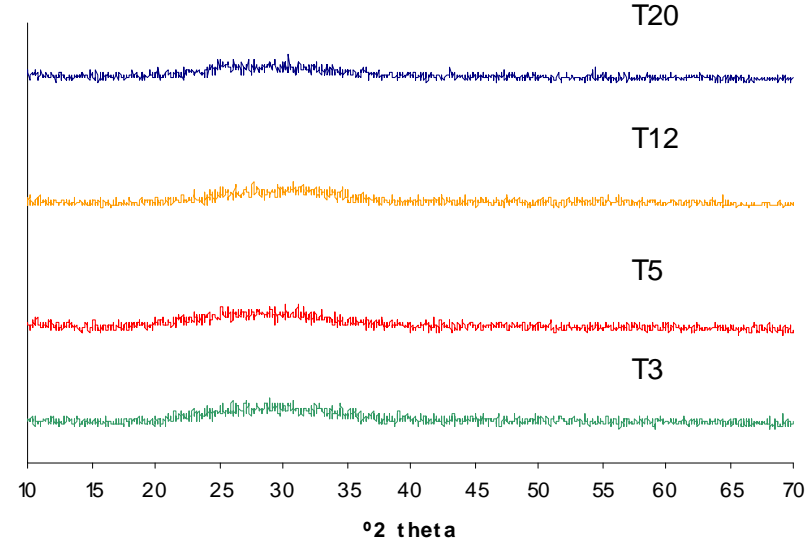

(101)

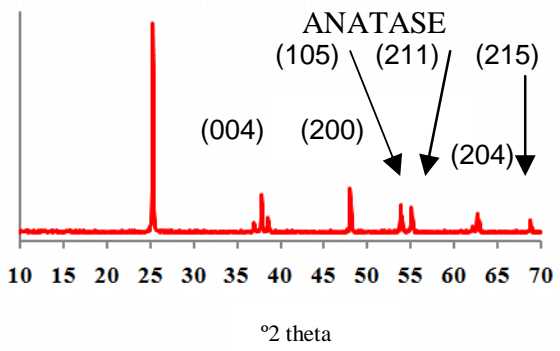

Fig 1 XRD patterns of fired powders at $600^{\circ} \mathrm{C} / 1 \mathrm{~h}$ and PANREAC anatase used as reference 


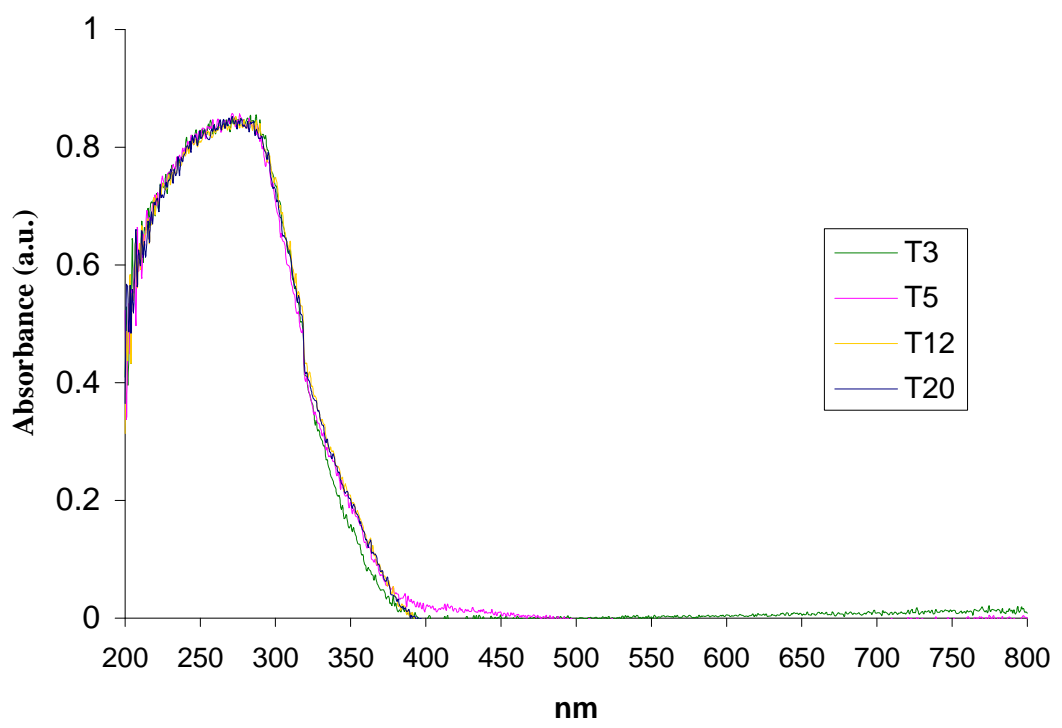

Fig. $2 \mathrm{UV}-\mathrm{Vis}$ spectra of fired powders at $600^{\circ} \mathrm{C} / 1 \mathrm{~h}$ 


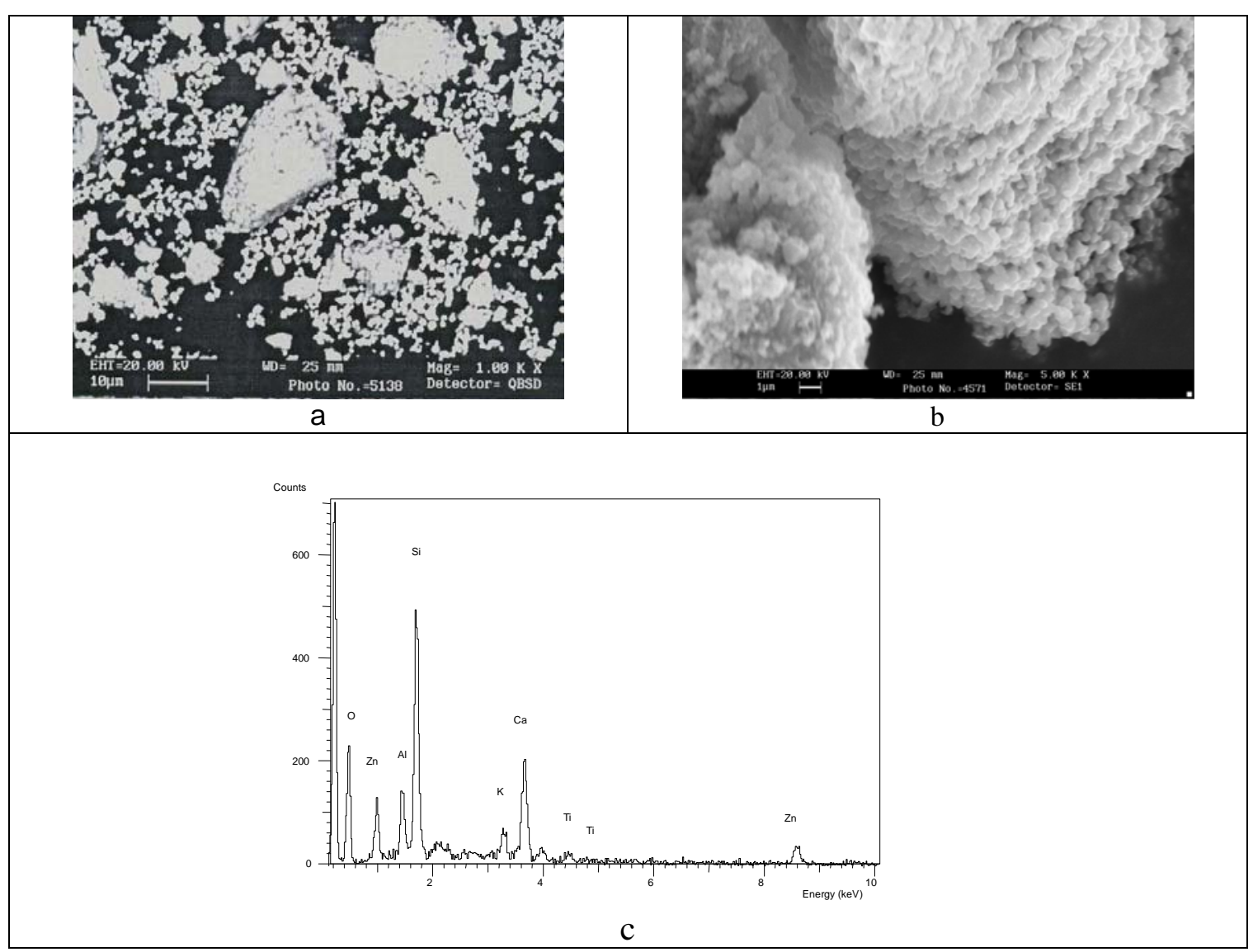

Fig. 3 The microstructure of representative sample (T3) fired at $600^{\circ} \mathrm{C} / 1 \mathrm{~h}$ and its chemical analysis EDX 


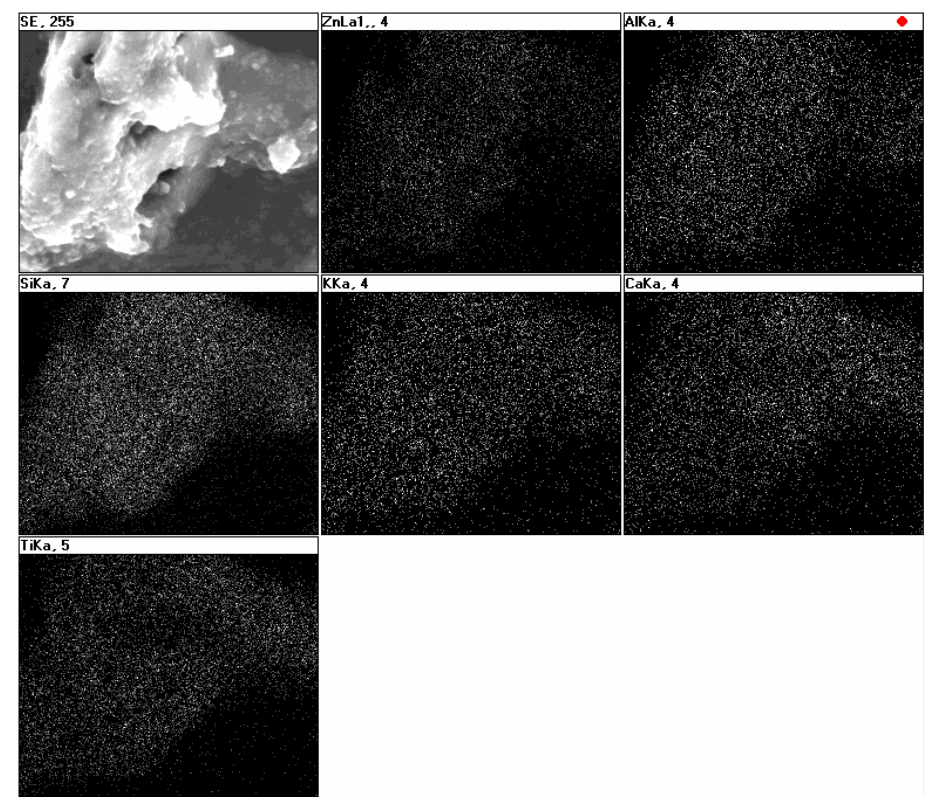

Fig 4 EDX mappings of T3 sample fired at $600^{\circ} \mathrm{C} / 1 \mathrm{~h}$ 


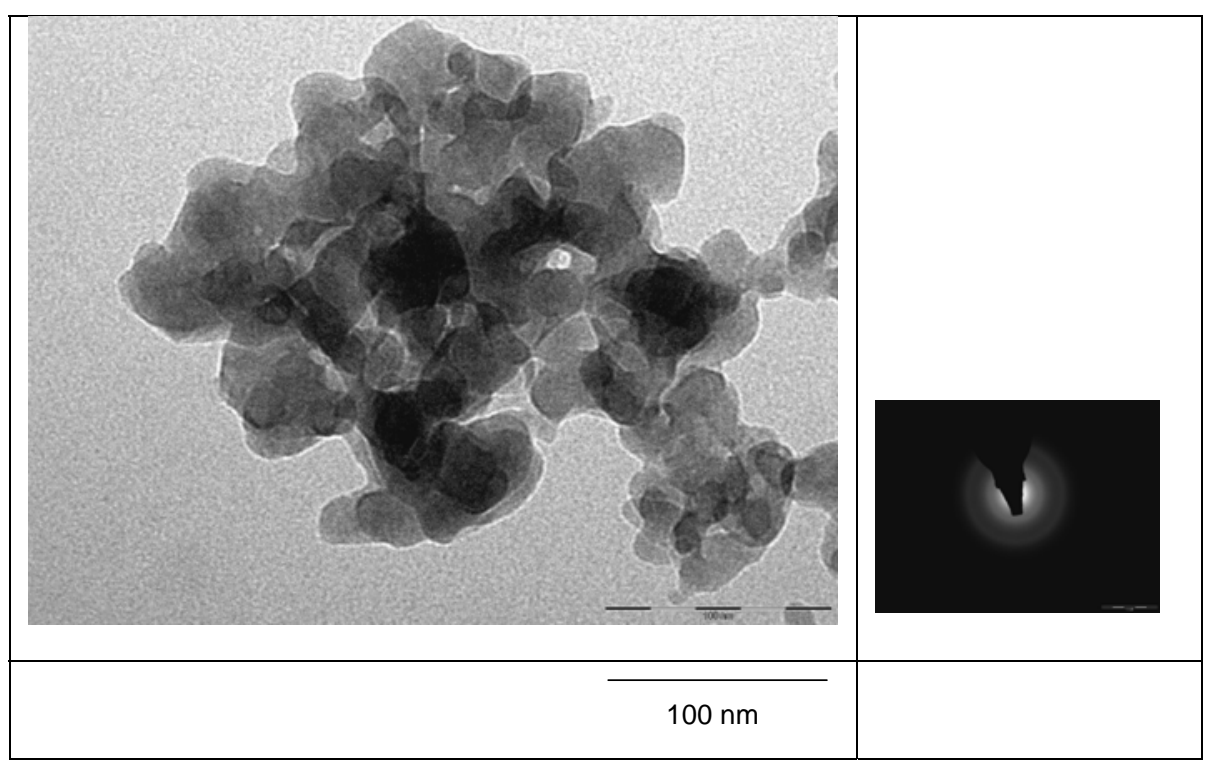

Fig. 5 TEM micrograph of T3 fired sample and SAED pattern of the same sample 


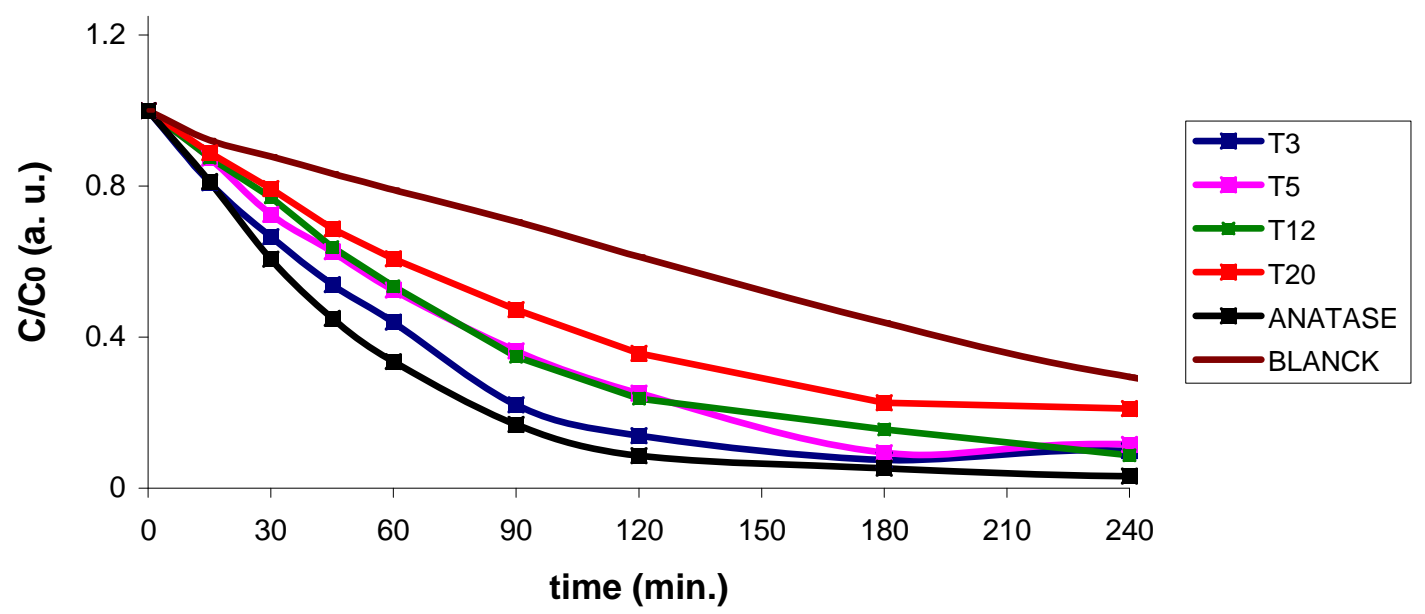

Fig 6 Photocatalytic degradation of orange II under UV light using blanck, anatase and prepared samples 